AperTO - Archivio Istituzionale Open Access dell'Università di Torino

G-CSF administration to adult mice stimulates the proliferation of microglia but does not modify the outcome of ischemic injury.

This is a pre print version of the following article:

Original Citation:

Availability:

This version is available http://hdl.handle.net/2318/80597

since

Published version:

DOI:10.1016/j.nbd.2010.11.013

Terms of use:

Open Access

Anyone can freely access the full text of works made available as "Open Access". Works made available under a Creative Commons license can be used according to the terms and conditions of said license. Use of all other works requires consent of the right holder (author or publisher) if not exempted from copyright protection by the applicable law. 


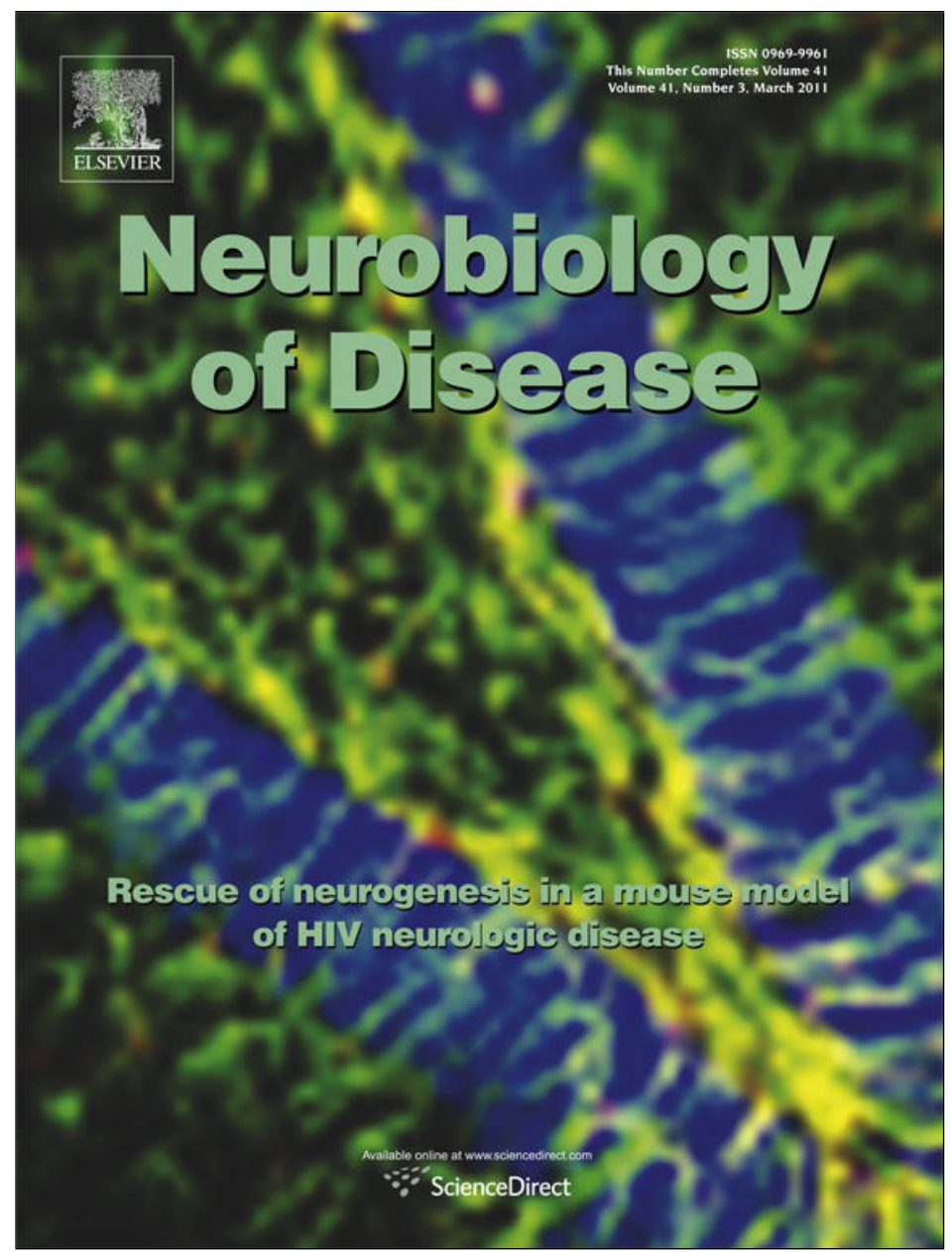

This article appeared in a journal published by Elsevier. The attached copy is furnished to the author for internal non-commercial research and education use, including for instruction at the authors institution and sharing with colleagues.

Other uses, including reproduction and distribution, or selling or licensing copies, or posting to personal, institutional or third party websites are prohibited.

In most cases authors are permitted to post their version of the article (e.g. in Word or Tex form) to their personal website or institutional repository. Authors requiring further information regarding Elsevier's archiving and manuscript policies are encouraged to visit:

http://www.elsevier.com/copyright 


\title{
G-CSF administration to adult mice stimulates the proliferation of microglia but does not modify the outcome of ischemic injury
}

\author{
Alice Bartolini ${ }^{\mathrm{a}, \mathrm{c}}$, Maria-Claudia Vigliani ${ }^{\mathrm{d}}$, Lorenzo Magrassi ${ }^{\mathrm{e}}$, Alessandro Vercelli ${ }^{\mathrm{b}, \mathrm{c}}$, Ferdinando Rossi ${ }^{\mathrm{a}, \mathrm{c}, *}$ \\ a Neuroscience Institute of Turin, Department of Neuroscience, Section of Physiology, University of Turin, I-10125 Turin, Italy \\ ${ }^{\mathrm{b}}$ Neuroscience Institute of Turin, Department of Anatomy, Pharmacology and Forensic Medicine, University of Turin, I-10125 Turin, Italy \\ ${ }^{\mathrm{c}}$ Neuroscience Institute of the Cavalieri-Ottolenghi Foundation (NICO), Italy \\ d 2nd Division of Neurology, Department of Neuroscience, University of Turin, Italy \\ e Neurosurgery, Department of Surgical Sciences, Fondazione IRCCS Policlinico San Matteo, University of Pavia, Italy
}

\section{A R T I C L E I N F O}

\section{Article history:}

Received 20 July 2010

Revised 12 October 2010

Accepted 16 November 2010

Available online 24 November 2010

\section{Keywords:}

G-CSF

Medial cerebral artery occlusion

Hematopoietic cells

Brain repair

Cell proliferation

Bone marrow

\begin{abstract}
A B S T R A C T
Recent evidence suggests that adult bone marrow stem cells reduce tissue damage and promote repair following CNS ischemic injury. Since granulocyte-colony stimulating factor (G-CSF) mobilizes hematopoietic stem cells to the circulating compartment, here we tested whether administration of this drug modifies the outcome of a permanent occlusion of the middle cerebral artery in adult mice. To elucidate the behavior and fate of bloodborne cells in the ischemic brain, we produced chimeric animals, in which hematopoietic derivatives are genetically tagged. G-CSF administration enhances the proliferation of microglia in the uninjured CNS but has no effect on the amount of hematopoietic cells that infiltrate the ischemic tissue and on the size of the lesion. The blood-borne elements acquire different mesodermal identities but fail to adopt neural phenotypes, even though they occasionally fuse with Purkinje neurons. These results indicate that G-CSF treatment does not exert a significant beneficial effect on the ischemic injury.
\end{abstract}

(C) 2010 Elsevier Inc. All rights reserved.

\section{Introduction}

Granulocyte-colony stimulating factor (G-CSF) is a hematopoietic growth factor that stimulates proliferation and specification of neutrophil precursors (Morrison et al., 1997; Wright et al., 2001) and induces their large-scale mobilization from bone marrow (BM) to the peripheral blood (Levesque et al., 2003; Zou et al., 2004; Katayama et al., 2006). Because of these properties, G-CSF has been widely used in clinical practice to treat neutropenia induced by chemotherapy, or in the case of BM transplantation (Welte et al., 1996). Recent studies highlighted the efficacy of GCSF in animal models of cerebral ischemia, reporting significant reduction of infarct size and improved functional recovery (Minnerup et al., 2008; Sevimli et al., 2009; Zhang et al., 2009). The beneficial effects of G-CSF have been attributed to different concurrent mechanisms, including antiapoptotic activity (Schäbitz et al., 2003; Schneider et al., 2005), immunomodulation (von Aulock et al., 2004), stimulation of neurogenesis (Schneider et al., 2005; Kawada et al., 2006; Diederich et al., 2009), and angiogenesis (Lee et al., 2005). These phenomena have been related to direct effects of G-CSF on neural cells or to enhanced colonization of ischemic regions by hematopoietic stem cells (HSCs) (Schäbitz and

* Corresponding author. Neuroscience Institute of the Cavalieri-Ottolenghi Foundation (NICO), Regione Gonzole 10, 10043 Orbassano (Turin), Italy. Fax: +39 0116705449.

E-mail address: ferdinando.rossi@unito.it (F. Rossi).

Available online on ScienceDirect (www.sciencedirect.com).
Schneider, 2007). The latter cells may produce and release molecules endowed with neuroprotective or neurotrophic activity (Schäbitz and Schneider, 2007; Hokari et al., 2009) but could also contribute directly to nervous tissue repair by adopting local phenotypes (Brazelton et al., 2000; Mezey et al., 2000) or fusing with damaged neurons (Magrassi et al., 2007).

The beneficial effects of G-CSF have been consistently observed following transient cerebral ischemia. Nevertheless, a dose-dependent expansion of cortical atrophy, associated with severe functional defects, has been reported following G-CSF administration in a model of permanent ligation of the middle cerebral artery (MCA) (Taguchi et al., 2007). These negative outcomes have been attributed to an exaggerated inflammatory response, consequent to the enhanced G-CSF-induced infiltration of the infarct region by hematopoietic cells.

In spite of such contrasting reports, and considering their relevance for a potential use of G-CSF in the clinical treatment of stroke, little is known about the behavior and fate of blood-borne cells that colonize the ischemic brain following G-CSF stimulation and the consequent effects on ischemic injury. To address these issues, here we evaluated the effect of G-CSF application following permanent occlusion of the medial cerebral artery (MCAo). In this context, to relate the effects of G-CSF administration to the mobilization of hematopoietic elements and to the extension of ischemic brain damage, we prepared chimeric mice in which blood cells had been tagged by enhanced Green Fluorescent Protein (eGFP) expression. 
Analysis of these animals was aimed at monitoring the G-CSF-induced infiltration of the ischemic brain and at identifying the phenotypes acquired by the blood-borne elements. Our results show a moderate but consistent activity of G-CSF on the uninjured brain but fail to disclose significant effects on the extent of the injury, on the amount of blood cells that colonize the ischemic region, and on their phenotypic differentiation.

\section{Materials and methods}

\section{Animals and surgical procedures}

Adult CD1 or C57BL/6 mice (body weight 20-30 g, age 3-6 months; Harlan, San Pietro al Natisone, Italy) were used for the study. All experimental procedures on living animals were performed according to the European Communities Council Directive of 1986 (86/609/EEC), the National Institutes of Health guidelines, and the Italian law for care and use of experimental animals (DL116/92) and were approved by the Italian Ministry of Health and the Bioethical Committee of the University of Turin. All efforts were made to minimize the number of animals used and their suffering. All surgical procedures and perfusions were carried out under deep general anesthesia obtained by means of intraperitoneal administration of ketamine $(100 \mathrm{mg} / \mathrm{kg}$; Ketavet; Bayer, Leverkusen, Germany) supplemented by xylazine ( $5 \mathrm{mg} / \mathrm{kg}$; Rompun; Bayer).

\section{Generation of chimeric mice}

Animals. The recipients of BM transplantation were $\mathrm{C} 57 \mathrm{BL} / 6$ chimeric mice (H-2b/CD45.2; Harlan, San Pietro al Natisone, Italy). Donor BM cells were obtained from 5 - to 10 -week-old male transgenic mice derived by outcrossing the original mice that ubiquitously express the enhanced Green Fluorescent Protein (eGFP) under control of the $\beta$ actin promoter (Okabe et al., 1997).

Conditioning and graft. Mice used as recipients of BM transplants were conditioned by irradiation with a total dose of $900 \mathrm{cGy}$ from a 60Co source $24 \mathrm{~h}$ before transplantation. Donor mice were killed by cervical dislocation, their femur and tibias were removed, and marrow was flushed out of the bones with serum-free, glucose-supplemented Earle medium (Invitrogen, San Giuliano Milanese, Italy), under sterile conditions. The suspension of BM-derived cells for grafting was obtained by mechanical dissociation of the marrow fragments. After washing three times and centrifugation, donor cells were resuspended in Earle medium to a final concentration of $10^{6}$ cells in $300 \mu \mathrm{l}$. In all recipient animals, the unfractionated marrow cell suspension was grafted by tail vein injection. Donor engraftment was determined by flow cytometry of peripheral blood. Cytometric analysis was performed on days 20 and 40 after bone marrow grafting. Chimeric mice were subjected to the MCAo surgery and to the consequent G-CSF/vehicle/BrdU protocol at about 4 months after the transplantation.

\section{Induction of ischemic lesion}

Focal cerebral ischemia was induced according to the model of Renolleau et al. (1998). This model of permanent MCAo was chosen because it yields consistent and repetitive results through animals, thus facilitating the quantitative assessment of cell proliferation and fate, which was the primary goal of our work. In addition, a similar model has been previously applied to investigate the effect of other neuroprotectants (de Bilbao et al., 2009; Wang et al., 2010). Briefly, mice were anesthetized (see above) and the left MCAo was obtained by electrocoagulating the MCA close to its origin at the junction with the olfactory branch. A clip was then placed to occlude the left common carotid artery (CCA) and was removed after $90 \mathrm{~min}$. Rectal temperature was maintained at $36.5-37.5^{\circ} \mathrm{C}$ throughout the procedure. Sham-operated mice received the same surgical procedures except that the MCA was not electrocoagulated and the CCA was not occluded. This procedure was applied because CCA ligation significantly reduces the high variability of infarct size after MCAo, due to anastomoses that protect the MCA territory from ischemia.

\section{Drug administration}

Human recombinant G-CSF (L03AA02 Filgrastim, Amgen, MI, Italy) was dissolved in a $5 \%$ glucose solution and intraperitoneally injected ( $50 \mu \mathrm{g} / \mathrm{kg} /$ day for 4 days, starting from 3 to $6 \mathrm{~h}$ after surgery) to ischemic or uninjured mice, whereas control animals received vehicle only. This daily dose of GCS-F is similar to that administered in most studies on experimental stroke, whereas the cumulative dose is among the highest used in such reports (Minnerup et al., 2008; Schäbitz and Schneider, 2007; England et al., 2009). The mice also received intraperitoneal injections of bromodeoxyuridine (BrdU, $50 \mathrm{mg} / \mathrm{kg}$ in saline, Sigma, St Louis, MO) twice a day during the same 4 days of cytokine/vehicle treatment, according to the same time schedule described above.

The animals were divided into several experimental groups: unlesioned mice with G-CSF $(n=4)$ or vehicle $(n=4)$, sham-operated mice with G-CSF $(n=4)$ or vehicle $(n=4)$, MCAo mice with G-CSF $(n=4)$ or vehicle $(n=4)$. These animals were killed 1 week after the beginning of the treatment. In contrast, the chimeric mice, which were specifically destined to the analysis of the fate of hematopoietic cells infiltrating the injured brain, were all subjected to MCAo and subdivided in two groups, receiving either G-CSF $(n=3)$ or vehicle $(n=3)$. These animals were killed 3 weeks after the beginning of the treatment to identify the mature phenotype acquired by hematopoietic cells.

\section{Histological procedures}

At the end of the survival time, under deep general anesthesia (see above), the animals were transcardially perfused with $500 \mathrm{ml}$ of $4 \%$ paraformaldehyde and $0.8 \%$ picric acid solution (Fluka, Buchs, Switzerland) in $0.12 \mathrm{M}$ phosphate buffer, $\mathrm{pH}$ 7.2-7.4. The brains were immediately dissected, stored overnight in the same fixative at $4{ }^{\circ} \mathrm{C}$, and finally transferred to $30 \%$ sucrose in $0.12 \mathrm{M}$ phosphate buffer, until they sank. The brains were cut with a cryostat in series of 30- $\mu$ m-thick coronal slices collected in PBS. The slices were immunohistochemically processed to detect the expression of different cell-specific antigens: Iba1 (1:1000, rabbit polyclonal, Wako), S100 (1:2000, rabbit polyclonal, DakoCytomation, Glostrup, DK), Olig2 (1:500, rabbit polyclonal, Chemicon), NeuN (1:500, mouse monoclonal, Chemicon), CD133 (alias Prominin1; 1:500, mouse monoclonal, eBioscience, San Diego, CA, USA), Flk (1:50, rat monoclonal, BD Biosciences, San Jose, CA, USA), factor VIII (von Willebrandt factor; 1:200, rabbit polyclonal; DakoCytomation, Glostrup, DK). In case of chimeric mouse tissue, we used anti-GFP antibodies (1:700, rabbit polyclonal or mouse monoclonal; Invitrogen, Carlsbad, CA) to enhance the intrinsic fluorescence of BM-derived cells. In addition, the proliferation studies were performed, thanks to the visualization of BrdU incorporation by means of anti-BrdU antibody (1:500, rat monoclonal; Abcam, Cambridge, UK). For BrdU immunohistochemistry, the slices were pre-incubated in $\mathrm{HCl} 2 \mathrm{~N}$ for $20 \mathrm{~min}$ at $37^{\circ} \mathrm{C}$, then washed in PBS and in borate buffer $(0.5 \mathrm{M}, \mathrm{pH} 8.5)$ for $10 \mathrm{~min}$ at room temperature.

Incubation with primary antibodies was made overnight at room temperature in PBS with $1.5 \%$ normal serum and $0.25 \%$ TritonX-100. For BrdU and eGFP labelling, in some cases, immunohistochemical staining was performed according to the avidin-biotin-peroxidase method (Vectastain ABC Elite kit; Vector Laboratories, Burlingame, CA, USA) and revealed using $3,3^{\prime}$-diaminobenzidine $(0.03 \%$ in Tris- $\mathrm{HCl})$ as a chromogen. The other series were processed for double immunofluorescence. These sections were then exposed for $1 \mathrm{~h}$ at room temperature to secondary biotinylated antibodies followed by a solution of streptavidin Texas Red conjugate (1:200; Invitrogen) or fluoresceinated second antibody (1:200; Vector Laboratories). The stained sections were 
mounted on microscope slides with Tris-glycerol supplemented with $10 \%$ Mowiol (Calbiochem, La Jolla, CA) to reduce fading of fluorescence.

\section{Data analysis}

The histological preparations were examined by means of a Zeiss (Oberkochen, Germany) Axiophot light microscope, equipped with a Nikon (Melville, NY) DS-5M digital camera. The material was also examined with an Olympus Optical (Hamburg, Germany) Fluoview 300 confocal microscope. Digital images were processed with Adobe Photoshop CS2 (Adobe Systems, San Jose, CA), to adjust contrast and assemble the final plates. Quantitative and morphometric evaluations were made using the softwares Image J (Research Service Branch, NIH, Bethesda, MD) and Neurolucida (MicroBrightField, Colchester, VT), the latter using a computer interfaced with an E-800 Nikon microscope equipped with a color CCD camera.

\section{Evaluation of lesion extension}

To evaluate the extent of the ischemic injury, we examined series of $30-\mu$ m-thick Nissl stained frontal sections, in which we distinguished uninjured tissue, penumbra, and necrotic core of the lesion. The boundary between intact tissue and penumbra was identifiable for the decrease of Cresyl Violet staining and the presence of apoptotic cells. Necrotic tissue was readily recognizable as disrupted tissue at the core of the injury. By means of Neurolucida, in each section of the series, we outlined the ischemic hemisphere and the affected tissue (i.e., penumbra plus core regions). From these data, the Neurolucida software calculated the respective volumes according to Cavalieri's geometry. Each of the reconstructions displayed in Fig. 6A-B encompasses the entire extension of the ischemic injury (total thickness of about $5 \mathrm{~mm}$, i.e., 25 sections).

\section{Quantitative analyses of cell proliferation and fate}

BrdU incorporation. In order to quantify the cellular proliferation in uninjured, ischemic, and sham-operated mice, we mapped BrdUpositive cells by Neurolucida and calculated the number of labeled nuclei per $\mathrm{mm}^{2}$. The analysis was carried out separately in several CNS subdivisions (e.g., neocortex, basal ganglia, hippocampus) or regions of interest (e.g., penumbra of the ischemic region), at two different levels along the rostro-caudal axis. On the whole, several thousand cells were sampled in each animal of the different experimental sets.

To assess whether G-CSF stimulates neurogenesis in the hippocampus of intact mice, we calculated the number of BrdU-positive cells along the length of the subgranular zone. For each animal, 200-250 labeled cells were mapped by means of Neurolucida in the hippocampi of both sides at four different levels along the rostro-caudal axis.

Phenotypic distribution of proliferating cells in intact mice. The identity of proliferating cells was assessed on double-immunostained material for BrdU and cell type-specific antigens (Iba1 for microglial cells, S100 for astrocytes and Olig2 for oligodendrocytes, NeuN for neurons). For each animal, several hundred cells were sampled and mapped in the hippocampi of both sides at different rostro-caudal levels and the number of double-labeled cells was expressed as percentage of total number of BrdU-positive nuclei.
BM-derived cells in chimeric mice. The density of eGFP-positive cells (number of eGFP-positive cells $/ \mathrm{mm}^{2}$ ) in chimeric mice was quantified as described above for BrdU incorporation. Briefly, by means of Neurolucida, we reconstructed the maps representing the distribution of bloodborne cells in several brain areas (neocortex, basal ganglia, hippocampus, penumbra of the lesion) at two different rostro-caudal levels.

To assess whether G-CSF increases the penetration of BM-derived cells in the intact nervous tissue, we counted the number of eGFPpositive cells $/ \mathrm{mm}^{2}$ in the cerebellum, by mapping at different rostrocaudal levels and sampling several hundred green cells per animal. The same material was used to monitor fusion events, by counting the number of eGFP-labeled Purkinje cells throughout the whole cerebellar cortex.

Phenotypic characterization in chimeric mice. Phenotype identification and relative frequencies of eGFP-positive cells were done by examining sections labeled for different type-specific markers. Several hundred cells were sampled for each animal, and the frequency of the different types was expressed as the percentage over the whole population of green cells contained within the sampled tissue.

\section{Statistical analysis}

The data are expressed as means \pm the standard deviations (SD). Statistical analysis was performed by comparing two groups with the unpaired Student's $t$-test. Differences were considered significant when $P<0.05$.

\section{Results}

G-CSF administration stimulates cell proliferation in the uninjured CNS

The main goal of our work was to assess the effects of G-CSF administration on the fate of BM-derived cells after ischemia and, hence, on the evolution of injury itself. Since G-CSF can cross the blood-brain barrier (Zhao et al., 2007a), we first examined intact animals to determine the direct effects of the substance on the CNS, and to set basal conditions to be compared with ischemic injury. Uninjured mice received injections of G-CSF or vehicle plus BrdU for 4 days and were killed 7 days after the beginning of the procedure. Compared to vehicle-injected animals, G-CSF-treated mice showed a clear-cut increase in the frequency of cells that incorporated $\mathrm{BrdU}$ in all the brain regions considered, including cerebral cortex, basal ganglia, and hippocampal formation (Fig. 1A-F). Quantitative evaluation, performed by mapping BrdUretaining nuclei at two different levels along the rostro-caudal axis (Fig. 1G), revealed no differences between the hemispheres in both groups (Fig. 1H; G-CSF-treated animals, Student's $t$-test, $P=0.703$; vehicle-treated animals, $P=0.806$ ), but showed a significant increase in the density of BrdU-positive cells after G-CSF administration (Fig. 1H; left hemisphere, Student's $t$-test, $P=0.037$, right hemisphere $P=0.047$ ). The same increase was consistently observed when different CNS subdivisions were evaluated separately (Fig. 1I, cerebral cortex, Student's $t$-test, $P=0.045$; basal ganglia, $P=0.043$; hippocampus, $P=0.012$ ).

The increase in BrdU incorporation in the hippocampus suggested that G-CSF administration could promote neurogenesis. However,

Fig. 1. G-CSF treatment stimulates proliferation of microglial cells in the uninjured CNS. A-F. Distribution of BrdU-positive cells in the cerebral cortex (A, D), hippocampus (B, E), and basal ganglia (C, F) of uninjured mice. Comparison of vehicle- $(A-C)$ and G-CSF-treated animals (D-F) reveals a consistent increase in the density of proliferating cells after drug administration. G. Examples of Neurolucida maps showing the distribution of BrdU-positive cells at two rostro-caudal levels. H, I. The graphs illustrate the density of BrdU-positive cells in control mice after vehicle and G-CSF administration. Analysis of entire hemispheres (H) or of individual brain regions (I) reveals a consistent effect of G-CSF. J-M. Double immunolabeling for BrdU (green) and NeuN (red) in the dentate gyrus does not reveal colocalization of the markers, as highlighted by the higher magnification insets (K, M), in which the position of BrdU-positive nuclei is indicated by arrows. N-S. Characterization of proliferating cells in uninjured mice treated with vehicle ( $\mathrm{N}-\mathrm{R}$ ) or with G-CSF (O-S). The micrographs show double-labeled cells (pointed by arrowheads) for BrdU (red) and Iba1 (green, N, O), S100 (green, P, Q), and Olig2 (green, R, S). T-V. Frequency of BrdU-labeled cells on the population of cells stained for Iba1, S100 or Olig2. CX, cerebral cortex; DG, dentate gyrus; Hippo, hippocampus; BG, basal ganglia; Ctrl, control; he., hemisphere. Asterisks represent statistically significant differences (see text for levels of significance). Scale bars: A, C, D, F, $400 \mu \mathrm{m}$; B, E, N-S, $20 \mu \mathrm{m}$; J, L, $40 \mu \mathrm{m}$; K, M, $10 \mu \mathrm{m}$. 

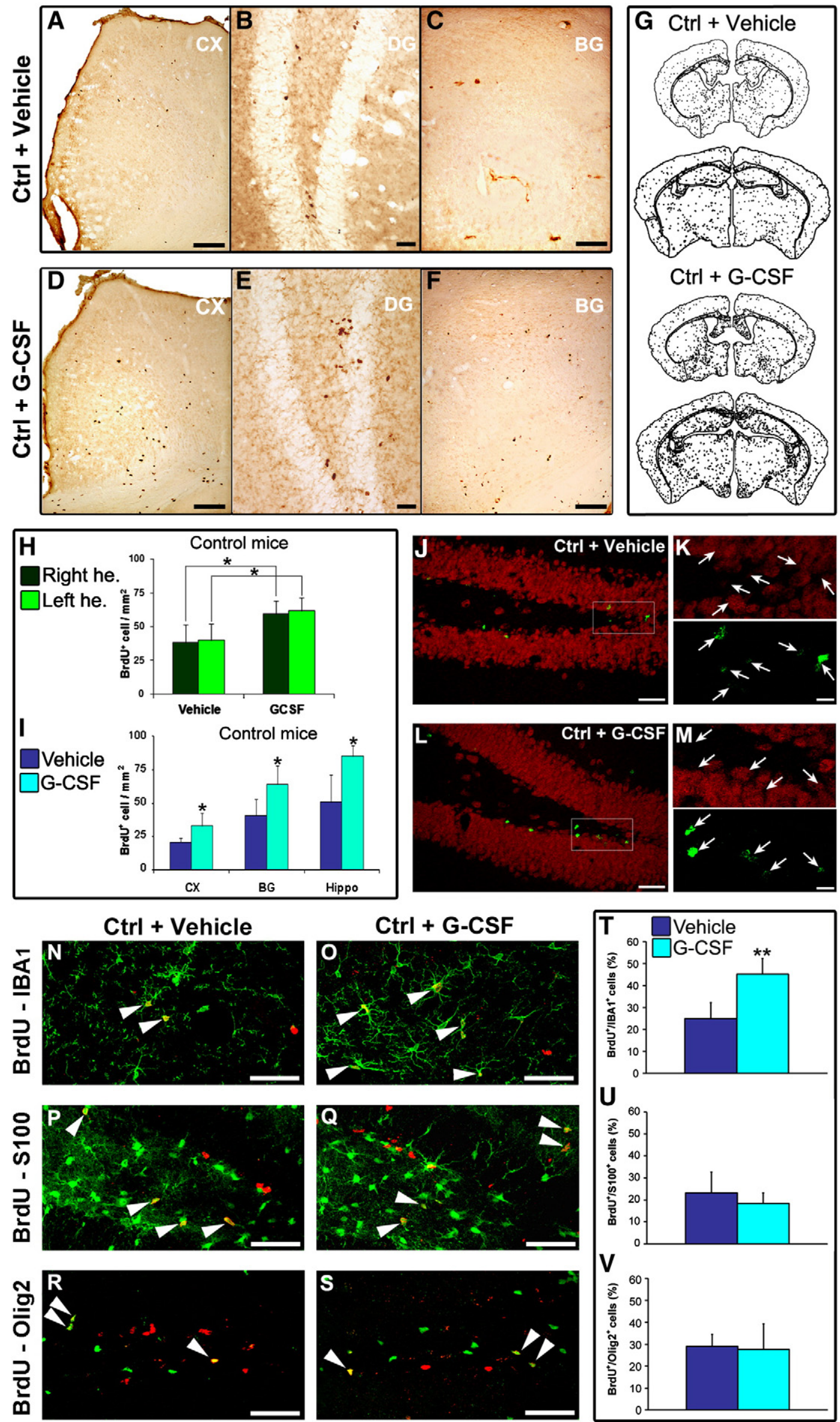
evaluation of the number of BrdU-positive nuclei along the extension of the subgranular zone (SGZ) did not reveal significant differences between G-CSF and vehicle-treated animals (BrdU-positive cells $/ \mathrm{mm}$ in G-CSF animals $=11.90 \pm 2.91$; in vehicle animals $=12.12 \pm 3.92$; Student's $t$-test, $P=0.895)$. Moreover, we failed to detect cells double-labeled for BrdU and NeuN in the SGZ or dentate gyrus of both experimental groups (Fig. 1J-M).

To characterize the cell types that proliferate following G-CSF treatment, we counted the number of cells double-labeled for BrdU and different lineage-distinctive markers in the hippocampus, where
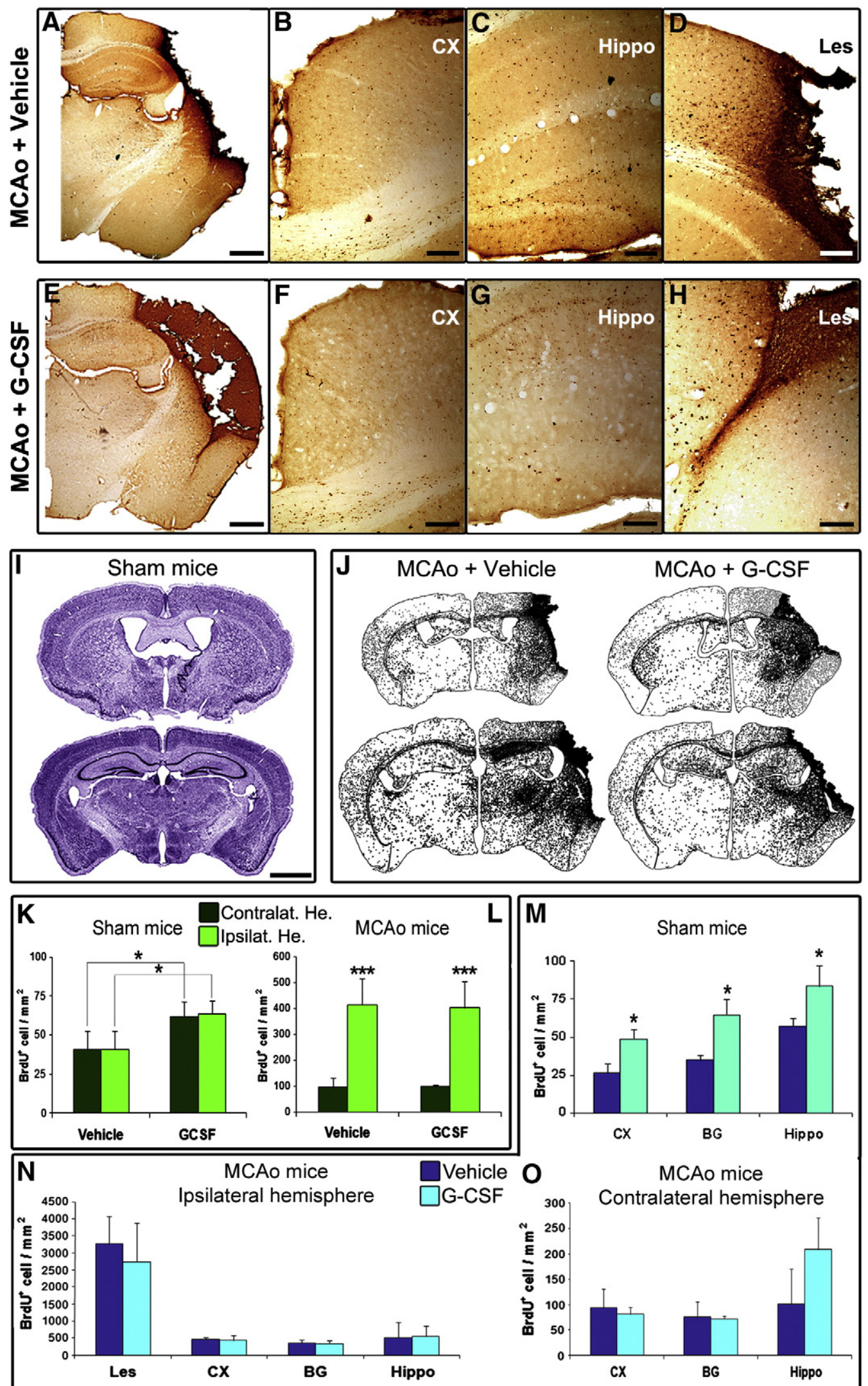

MCAo mice

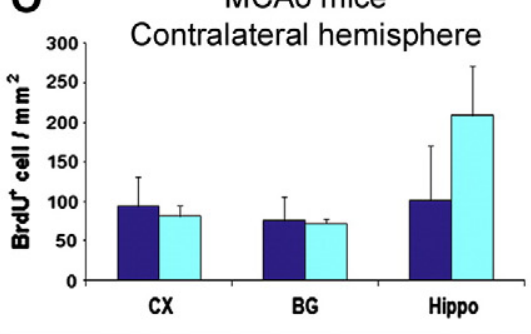



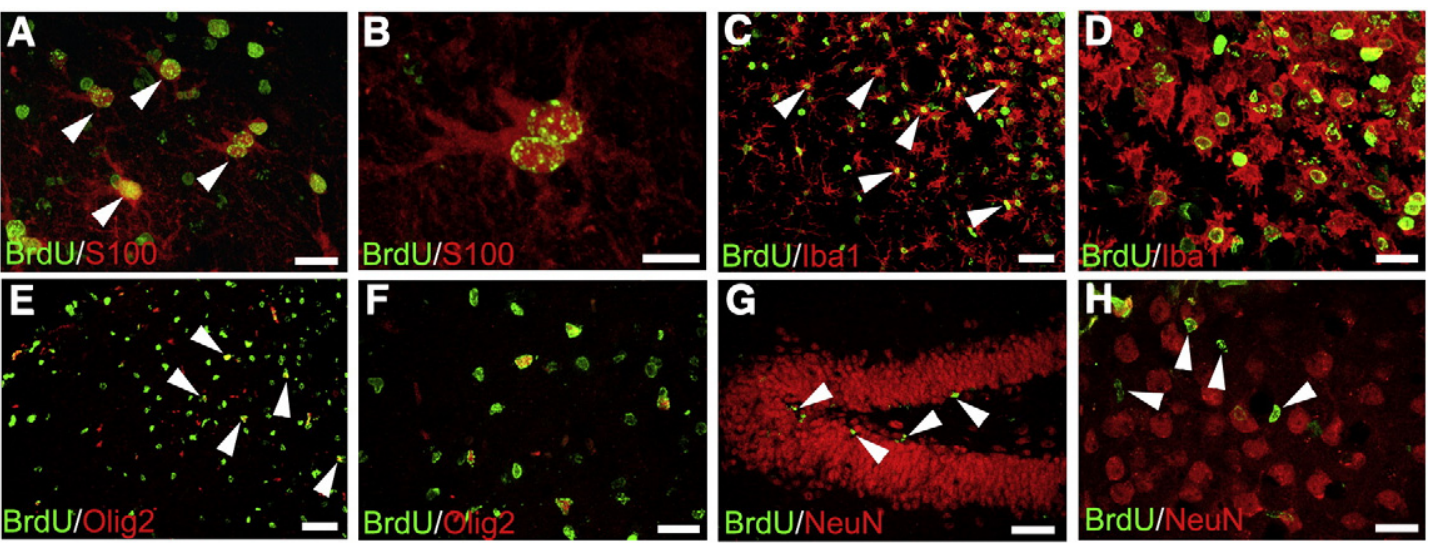

Fig. 3. Characterization of proliferating cells in the ischemic brain. The pictures represent double-labeled cells for BrdU (green) and type-specific antigens (red). Proliferating S100positive astrocytes (A, B, arrowheads), Iba1-positive microglial cells (C, D, arrowheads), and Olig2-expressing oligodendrocytes (E, F, arrowheads) can be detected in the vicinity of the lesion. On the contrary, no NeuN-positive nuclei are also labeled with BrdU (arrowheads), both in the hippocampus $(G)$ and in the cerebral cortex (H) ipsilateral to the injury. Scale bars: A, B, H $10 \mu \mathrm{m}$; E, C, $40 \mu \mathrm{m} ; \mathrm{F}, \mathrm{D}, 20 \mu \mathrm{m} ; \mathrm{G}, 50 \mu \mathrm{m}$

the highest density of labeled nuclei was encountered. In the G-CSFtreated animals, there was a significant increase of cells double-labeled for BrdU and the microglial marker Iba1 (Imai et al., 1996; Fig. 1N, $\mathrm{O}$, T; Student's $t$-test, $P=0.007)$. On the contrary, no differences between $\mathrm{G}$-CSF and vehicle-treated groups were found for S100-positive astrocytes (Fig. 1P, Q U; Student's t-test, $P=0.406$ ) and Olig-2-positive oligodendrocytes (Fig. 1R, S, V; Student's $t$-test, $P=0.842$ ). Therefore, the increase in the number of BrdU-positive cells in the intact CNS after G-CSF treatment appears to be exclusively sustained by microglia.

\section{Effect of G-CSF administration on cell proliferation in the ischemic brain}

To assess whether G-CSF influences cell proliferation in the injured nervous tissue, we applied the same protocol of BrdU/G-CSF or BrdU/vehicle administration starting from the day when MCAo was performed. In the brains of the sham-operated mice, there were no signs of tissue injury (Fig. 2I), and the pattern of incorporation of BrdU was similar to that observed in the intact mice (Fig. $2 \mathrm{~K}, \mathrm{M}$ ). Following ischemia, the density of BrdU-retaining cells was strongly increased in both hemispheres (Fig. 2A-H, J), although labeled nuclei on the injured side greatly outnumbered those on the contralateral side (Fig. 2L; G-CSF-treated animals, Student's t-test, $P=0.009$; vehicle-treated animals, $P=0.005$ ). The values calculated from ischemic brains were considerably higher than those obtained from sham-operated mice (Fig. 2K-0; Student's t-test, ischemic hemisphere vs. sham hemisphere $P<0.005$ for both G-CSF and vehicle-treated mice). On the other hand, no significant differences were found between G-CSF and vehicle-treated animals in either hemisphere (Fig. 2L; injured side, Student's $t$-test, $P=0.878$; contralateral side, $P=0.904)$. The same result was obtained by analyses restricted to the ischemic area or to the different CNS subdivisions (Fig. 2N, O), except for a higher number of BrdUlabeled cells in the uninjured hippocampus, which nonetheless failed to reach statistical significance (Fig. 20; ipsilateral hemisphere: lesion, Student's t-test, $P=0.477$; cortex, $P=0.741$; basal ganglia, $P=0.846$; hippocampus, $P=0.902$; contralateral hemisphere: cortex, $P=0.548$; basal ganglia, $P=0.845$; hippocampus, $P=0.061)$. Phenotypic characterization of BrdU-labeled cells revealed S100-positive astrocytes (Fig. 3A, B), Iba1-positive microglia (Fig. 3C, D), and Olig2-positive oligondrocyte precursors (Fig. 3E, F). On the contrary, we failed to observe cells double-labeled for BrdU and the neuronal marker NeuN (Fig. 3G, H).

The infiltration of BM-derived cells in the ischemic injury site is not influenced by G-CSF administration

To assess whether G-CSF promotes the infiltration of blood-borne cells in the ischemic tissue, we induced permanent MCAo in chimeric mice, in which hematopoietic elements had been replaced by eGFPexpressing cells. In order to identify the mature phenotypes acquired by the immature blood cells recruited into the lesioned parenchyma, these animals were killed 3 weeks after surgery (followed by G-CSF/ BrdU or vehicle/BrdU administration protocol).

We first asked whether G-CSF facilitates the ability of BM-derived cells to colonize the intact CNS tissue. Since all chimeric animals underwent MCAo, we evaluated the frequency of eGFP-positive cells in the cerebellum, which is not directly affected by the ischemic insult. This analysis did not reveal any difference in the number of BrdU-positive cells $/ \mathrm{mm}^{2}$ between drug or vehicle-treated groups (G-CSF $=37.17 \pm$ 7.19; vehicle $=39.34 \pm 8.47$; $t$-test $P$ value $=0.752$ )

Analysis of the histological sections of the hemispheres revealed similar distribution patterns of eGFP-positive cells after G-CSF or vehicle administration (Fig. 4A-I). BM-derived cells were preferentially located inside or surrounding the ischemic lesion, although they were present throughout the examined tissue. Green cells were more frequent in the injured than in the intact hemisphere (Fig. 4J), but there were no clear differences between G-CSF and vehicle-treated mice, although the number of green cells $/ \mathrm{mm}^{2}$ in the hemisphere contralateral to MCAo was slightly higher in the latter group (Fig. 4J; Student's $t$-test, $P=0.037$ ).

Fig. 2. G-CSF administration does not affect proliferation following ischemic damage. A-H. Distribution of BrdU-positive cells in the whole ischemic hemisphere (A, E), cerebral cortex (B, F), hippocampus (C, G), and ischemic area (D, H) of G-CSF- (E-H) and vehicle-treated mice (A-D). I. Nissl-stained sections show the absence of CNS injury in shamoperated mice. J. Examples of Neurolucida maps showing the distribution of BrdU-positive cells at two rostro-caudal levels. K-L. The graphs illustrate the density of BrdU-positive cells in the entire hemispheres of G-CSF and vehicle-injected mice that underwent sham surgery (K) or MCAo (L). In sham mice, G-CSF induced a significant increase of proliferating cells in both hemispheres (Student's $t$-test, $P<0.01$ ). In contrast, following MCAo, there was a huge increase of BrdU-labeled nuclei, particularly in the injured hemisphere. However, no difference was observed between G-CSF and vehicle-treated animals. M-O. Analysis of individual CNS regions yielded similar results: the moderate increase of BrdU labeling consistently observed following G-CSF administration to sham animals (M; Student's $t$-test, $P<0.01$ ) was masked by the huge effect of ischemic injury ( $\mathrm{N}$, $\mathrm{O}$; please note the different scales of the graphs showing data from sham and MCAo mice). MCAo, middle cerebral artery occlusion; CX, cerebral cortex; Hippo, hippocampus; Les, lesion; Ipsilat. He., ipsilateral hemisphere; Contralat. He., contralateral hemisphere; BG, basal ganglia. Asterisks represent statistically significant differences (see text for levels of significance). Scale bars: A, E, $2000 \mu \mathrm{m}$; B-D, F-H, $400 \mu \mathrm{m}$; I, $4000 \mu \mathrm{m}$. 

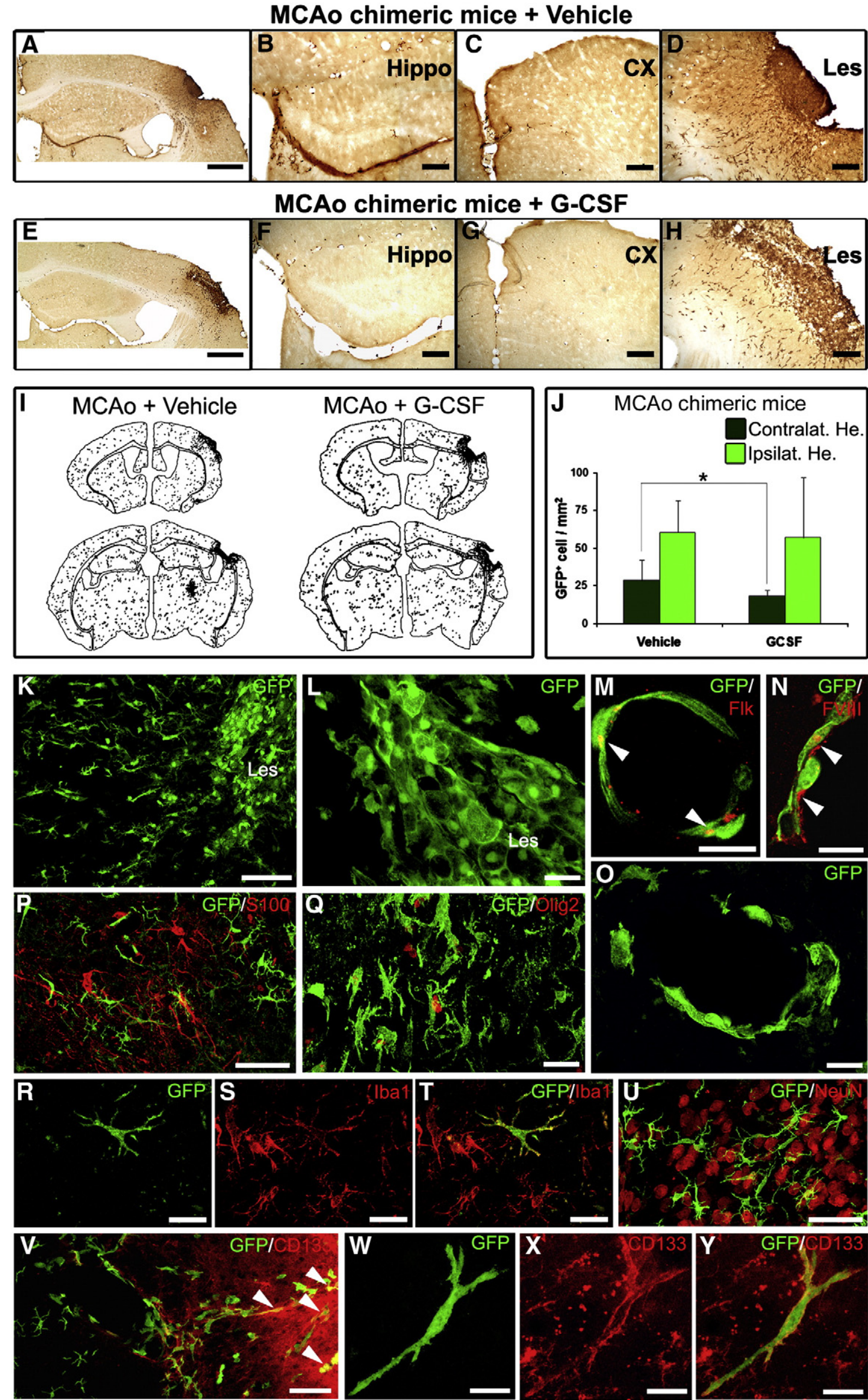

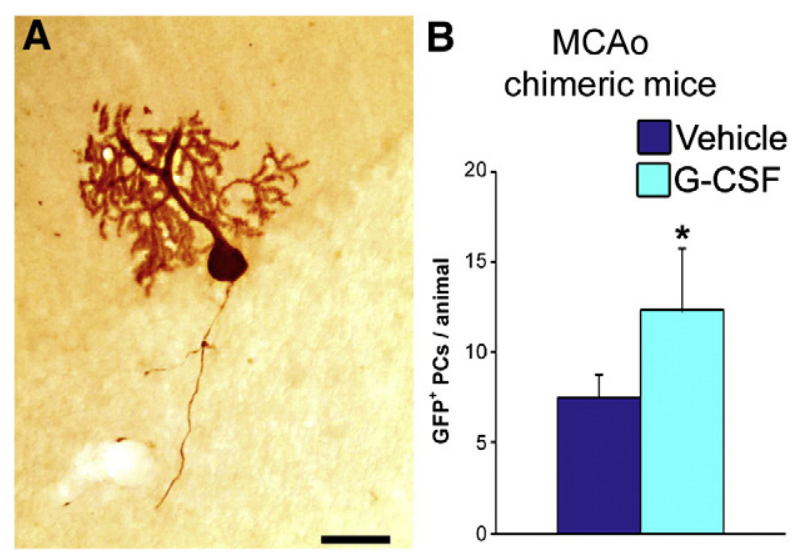

Fig. 5. G-CSF increases fusion of BM-derived cells with Purkinje neurons. A. A cerebellar Purkinje cell expressing eGFP after fusion with a BM-derived cell in a chimeric mouse. B. Quantification of eGFP-positive Purkinje cells in chimeric mice treated with vehicle or G-CSF. MCAo, middle cerebral artery occlusion. Asterisks represent statistically significant differences (see text for levels of significance). Scale bar: $100 \mu \mathrm{m}$.

The majority of BM-derived cells that infiltrate the ischemic tissue differentiate into activated microglia and macrophage-like cells

To identify the mature phenotype acquired by the BM-derived cells in the tissue surrounding the ischemic core, we analyzed their morphology and the expression of cell type-specific markers. eGFPpositive cells that infiltrate the ischemic penumbra showed features suggestive of migratory behavior (Fig. 4K), whereas those located in the irreversible ischemic core were tightly clustered and exhibited the round-shaped and vacuolar morphology of activated macrophages (Fig. 4L).

The phenotypic analysis of eGFP-positive cells present in the injured tissue revealed a rather wide repertoire of cell types but failed to disclose any difference between G-CSF and vehicle-treated groups. Some green cells were co-labeled with CD-133, which is distinctive for immature hematopoietic cells (Wognum et al., 2003; Corbeil et al., 2001) (Fig. 4V-Y; G-CSF: $7.41 \pm 1.18 \%$ of eGFP-positive cells; vehicle: $6.37 \pm 0.62 \%$; Student's t-test, $P=0.268$ ). A conspicuous amount of small eGFP-expressing cells with several tiny processes were labeled by the microglial marker Iba1 (Fig. 4R-T; G-CSF: $41.28 \pm 9.37 \%$, vehicle: $49.55 \pm 0.77 \%$; Student's $t$-test, $P=0.265$ ), whereas a smaller fraction showed the morphological features and neurochemical profiles of endothelial cells (Fig. 4M-O; G-CSF: $4.92 \pm 0.84 \%$; vehicle: $3.62 \pm 1.41 \%$; Student's $t$-test, $P=0.257)$. Concerning neural phenotypes, we never observed any green-fluorescent cell displaying structural features and typedistinctive markers of astrocytes (Fig. 4P), oligodendrocytes (Fig. 4Q), or neurons (Fig. 4U). Within the whole brain, the only green cells with neuronal morphology were some Purkinje cells scattered through the cerebellar cortex, whose eGFP expression results from the fusion with hematopoietic cells (Alvarez-Dolado et al., 2003; Magrassi et al., 2007). Interestingly, such neurons were more numerous in G-CSF-treated animals than in the vehicle-treated group (Fig. 5A, B; Student's $t$-test, $P=0.048$ ).

\section{MCAo + Vehicle}
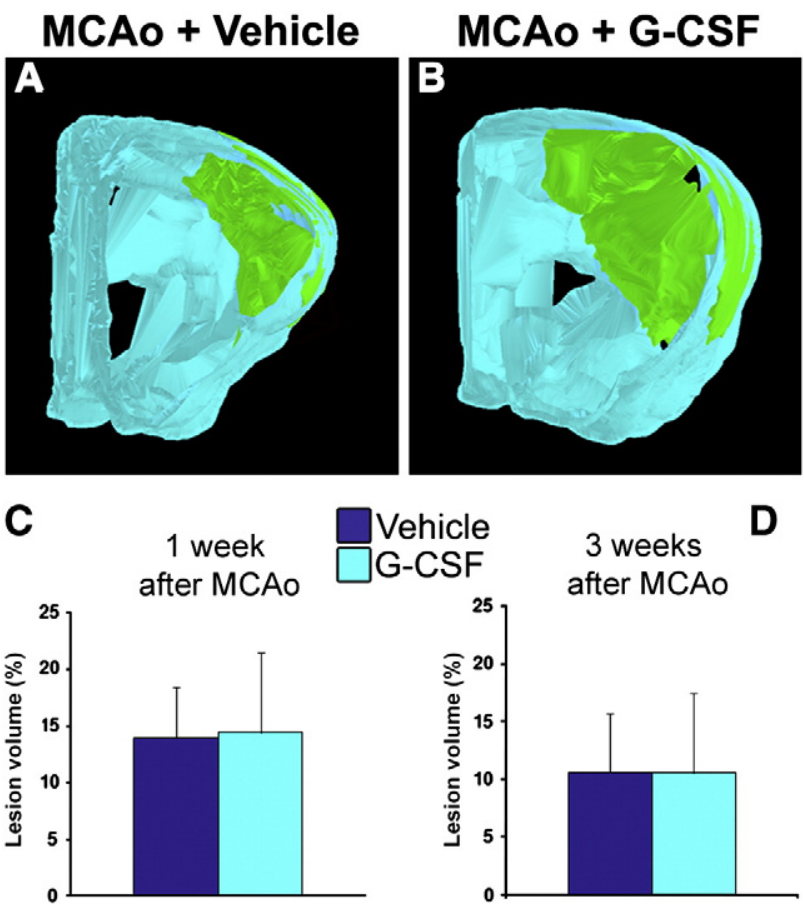

Vehicle G-CSF 3 weeks after MCAo

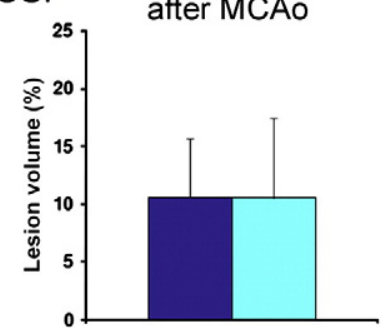

Fig. 6. Effects of G-CSF treatment on the size of the ischemic injury. A-B. Three dimensional reconstructions of the ischemic hemispheres in vehicle- (A) and G-CSFtreated mice (B), obtained by analysis with Neurolucida of Nissl-stained serial sections. In this graphic illustration, the lesion is represented in green, while the tissue of the ipsilateral hemisphere is depicted in light blue. Each reconstruction encompasses the entire extension of the ischemic lesion (total thickness about $5 \mathrm{~mm}$ ). C-D. Comparison of injury volumes, represented as percentage of the ipsilateral hemisphere, in vehicle and G-CSF-treated mice, 1 (C) or 3 weeks (D) after MCAo. MCAo, middle cerebral artery occlusion.

\section{G-CSF does not reduce the extent of the ischemic injury}

To ask whether G-CSF administration modifies the extension of the ischemic injury, we produced serial section reconstructions of the affected hemispheres to measure the volume of the lesion 1 and 3 weeks after MCAo (Fig. 6A, B). Comparison of the lesion volumes, expressed as the percentage of the respective hemisphere, did not reveal any significant difference at either time points (Fig. 6C, D; Student's t-test, $P=0.907)$.

\section{Discussion}

Starting from recent evidence suggesting that BM-derived stem cells promote repair and recovery following ischemic brain injury, we asked whether pharmacological mobilization of these cells can help to ameliorate the outcome of permanent MCAo, a condition that reproduces the features of human ischemic stroke (STAIR, 1999; Mohr et al., 2004). Our results show that, although G-CSF stimulates mitotic activity of microglia in the intact brain, it has no clear promoting effect on the proliferation of blood-borne cells and on their ability to infiltrate

Fig. 4. Fate of BM-derived cells in the ischemic tissue. A-H. Distribution of eGFP-positive cells in the dorsal half of the hemisphere ipsilateral to the lesion (A, E), hippocampus (B, F), cerebral cortex (C, G), and inside the damaged tissue (D, H) of chimeric mice treated with vehicle (A-D) or G-CSF (E-H). I. Examples of Neurolucida maps showing the distribution of BrdU-positive cells at two rostro-caudal levels. J. The graph illustrates the density of eGFP-positive cells in the entire hemisphere of both G-CSF and vehicle-injected chimeric mice. K-L. Morphology of eGFP-positive cells in the ischemic tissue. M-Y. Phenotypic characterization of BM-derived cells (green) by immunolabeling with type-specific markers (red): many of the green cells are stained for endothelial markers (Flk, M; factor VIII, N; pointed by arrowheads) and display endothelial morphology (O). BM cells do not stain for macroglial (S100, P; Olig2, Q) or neuronal (NeuN, U) antigens, but they are labeled by the microglial marker Iba1 (R-T). In addition, numerous green cells located near to the ischemic site are stained by CD133 antibody (V-Y; pointed by arrowheads in V). MCAo, middle cerebral artery occlusion; Hippo, hippocampus; CX, cerebral cortex; Les, lesion; Ipsilat. He., ipsilateral hemisphere; Contralat. He., contralateral hemisphere. Asterisks represent statistically significant differences (see text for levels of significance). Scale bars: A, E, $1000 \mu \mathrm{m} ; \mathrm{B}-\mathrm{D}, \mathrm{F}-\mathrm{H}, 200 \mu \mathrm{m} ; \mathrm{K}, 100 \mu \mathrm{m} ; \mathrm{L}-\mathrm{N}, \mathrm{O}, \mathrm{R}-\mathrm{T}, \mathrm{W}-\mathrm{Y}, 10 \mu \mathrm{m}$; P, U, $\mathrm{V}, 50 \mu \mathrm{m} ; \mathrm{Q}, 20 \mu \mathrm{m}$. 
the injured tissue. Accordingly, the size of the ischemic damage is not significantly reduced. Therefore, our observations indicate that, at least in the present experimental conditions, G-CSF treatment has no major effect on the outcome of the ischemic injury.

\section{Effects of G-CSF administration in the intact CNS}

In intact or sham-operated animals, G-CSF treatment induced a clear-cut increase in BrdU incorporation that was consistent in all the examined telencephalic regions. Phenotypic characterization of the proliferating populations showed that this effect exclusively involved microglia, whereas neural lineages were unaffected. In addition, in spite of the increased frequency of BrdU-labeled nuclei in the hippocampus of G-CSF-treated mice, no difference was found in the subgranular zone, indicating that the cytokine does not promote neurogenic processes. These results were somewhat surprising, given that both G-CSF and the cognate receptor are expressed by adult intact neurons (Schneider et al., 2005). It is likely that, at the doses used in our study, the exogenous G-CSF does not add much to the effect exerted by the endogenously produced substance. Thus, although our data do not exclude the proposed neurogenic and anti-apoptotic role played by G-CSF on neurons, they fail to show an additive effect induced by the pharmacological administration of the cytokine.

The increase of BrdU incorporation in microglia could be due either to direct stimulation of proliferation in resident cells in the CNS parenchyma or enhanced infiltration by blood-borne elements. Our analysis of uninjured regions (the cerebellum) in the chimeric mice does not favor the latter explanation, since we did not find more eGFPpositive cells in the cerebella of G-CSF-treated animals. In this context, the higher frequency of fusion with Purkinje cells (Alvarez-Dolado et al., 2003; Magrassi et al., 2007) is also consistent with a direct stimulating effect of the drug on microglia. Indeed, fusion events in the cerebellar cortex are increased following injury and activation of microglia (Magrassi et al., 2007). Therefore, our observations indicate that systemically administered G-CSF influences the behavior of cells residing in the CNS but does not increase CNS colonization by circulating cells.

\section{Effects of G-CSF administration on the ischemic CNS}

Following ischemia, G-CSF treatment had no effect on cell proliferation or on the infiltration of eGFP-positive cells in the lesioned tissue. The densities of BrdU-positive nuclei or of green cells in ischemic regions were several fold higher than those estimated in intact brains. MCAo severely disrupts the blood-brain barrier and induces a strong tissue reaction to the ischemic insult (Fagan et al., 2004). These phenomena are associated with the release of a wide range of bioactive molecules, including cytokines such as G-CSF (Schäbitz et al., 2003; Komine-Kobayashi et al, 2006), and massive infiltration of circulating cells (leucocytes, Yilmaz and Granger, 2010; mast cells, Strbian et al., 2009). These incoming blood-borne cells play different roles in the evolution of brain infarct. For example, mast cells may contribute to disrupt the blood-brain barrier and favor hemorrhage, whereas their stabilization leads to reduction of brain oedema and infarct size (Strbian et al., 2009). On the other hand, activation of immune cells may be neuroprotective and beneficial to repair phenomena (Stoll et al., 1998). Recently, it has been shown that accumulation of microglia precedes that of macrophages, lymphocytes, dendritic cells, and neutrophils (Gelderblom et al., 2009). Macrophages and microglia have been reported to gather preferentially in the penumbra, where they proliferate (Schroeter et al., 1999). Microglia are a double-edged sword, since they produce toxic molecules and proinflammatory cytokines, but they also release molecules involved in tissue repair (Gelderblom et al., 2009). The intensity of these phenomena clearly overwhelms the activity of the exogenous G-CSF and masks its direct effects, as also proposed by Komine-Kobayashi et al. (2006).
In line with these observations is the failure of G-CSF to reduce the infarcted volume. Indeed, previous studies on the effect of G-CSF treatment in experimental ischemia reported somewhat controversial results, including reduction of the injury size and improved recovery (Six et al., 2003; Lee et al., 2005; Schneider et al., 2005; Kawada et al., 2006; Komine-Kobayashi et al., 2006; Morita et al, 2007; Sehara et al, 2007; Zhao et al, 2007b,c; Toth et al, 2008; Solaroglu et al., 2009; for review see Minnerup et al., 2008; Bråtane et al., 2009), no significant effect (Popp et al, 2009), and even increased extension of the lesioned tissue (Taguchi et al., 2007). Comparison of the published data, however, is hampered by the high variability of experimental conditions, concerning the procedures used to induce ischemia and the methods applied to evaluate the time course of the consequent phenomena. In particular, a recent systematic review of the literature concluded that G-CSF induces a significant reduction of the injured tissue in case of transient but not permanent models of ischemic stroke (England et al., 2009). In addition, in some studies, beneficial effects are only observed when G-CSF is combined with other injury-induced cytokines (Zhao et al, 2007c). Taken together, these observations indicate that the efficacy of G-CSF application depends on several concurrent conditions, whose definition is crucial in the perspective of a therapeutic use.

To gain further insights about the phenotype and fate of BMderived cells in the ischemic injury, we generated chimeric mice in which these cells are tagged with eGFP. Three weeks after injury, huge amounts of green cells had colonized the damaged area and the surrounding tissues, including wide regions of both hemispheres. The cells in the ischemic core showed typical features of macrophages, whereas elsewhere, they mostly acquired the morphology and neurochemical profiles of microglia or endothelium. Some of the cells remained undifferentiated, but none of them adopted neural identities. This phenotypic repertoire was qualitatively and quantitatively similar in both experimental groups, showing that G-CSF did not influence the fate choice and differentiation of BM-derived cells.

On the whole, our observations indicate that G-CSF administration has no major beneficial effect on the outcome of CNS ischemia. In particular, the drug did not overtly affect the quality and the quantity of circulating BM-derived cells that infiltrate the injured CNS tissue. These cells should be responsible for stimulating compensatory phenomena and repair (Schwarting et al., 2008). Hence, the failure of G-CSF to promote their colonization of the injured tissue explains the lack of positive outcomes. Nonetheless, the valuable activity of the substance, which is witnessed by its clear effect on the intact CNS, should not be disregarded. Indeed, it is likely that significant results can only be obtained by combining different molecules with complementary properties and synergistic mechanisms of action and targets (Liu et al., 2010). In other words, an efficient treatment to ameliorate the evolution of ischemic CNS injury requires a cocktail of molecular mediators applied through specifically tailored spatio-temporal schedules.

\section{Acknowledgments}

We thank Francesco Frassoni for initial help in generating the hemopoietic chimeras. F.R. was supported by grants from Ministero dell'Università e della Ricerca Scientifica e Tecnologica (MIUR-PRIN 2007 prog. no. 2007F7AJYJ), Regione Piemonte (Project A14/05; Ricerca Sanitaria Finalizzata, 2008, 2009), Fondazione Cavaliere del Lavoro Mario Magnetto of Turin. L.M. was supported by grants from MIUR (PRIN 20074MW29N-004 2007), Ministero della Salute (RC cod. 08016098/07).

\section{References}

Alvarez-Dolado, M., Pardal, R., Garcia-Verdugo, J.M., Fike, J.R., Lee, H.O., Pfeffer, K., Lois, C., Morrison, S.J., Alvarez-Buylla, A., 2003. Fusion of bone-marrow-derived cells with Purkinje neurons, cardiomyocytes and hepatocytes. Nature 425, 968-973. Bråtane, B.T., Bouley, J., Schneider, A., Bastan, B., Henninger, N., Fisher, M., 2009 Granulocyte-colony stimulating factor delays PWI/DWI mismatch evolution and 
reduces final infarct volume in permanent-suture and embolic focal cerebral ischemia models in the rat. Stroke 40, 3102-3106.

Brazelton, T.R., Rossi, F.M., Keshet, G.I., Blau, H.M., 2000. From marrow to brain: expression of neuronal phenotypes in adult mice. Science 290, 1775-1779.

Corbeil, D., Röper, K., Fargeas, C.A., Joester, A., Huttner, W.B., 2001. Prominin: a story of cholesterol, plasma membrane protrusion and human pathology. Traffic 2, 82-91.

de Bilbao, F., Arsenijevic, D., Moll, T., Garcia-Gabay, I., Vallet, P., Langhans, W., Giannakopoulos, P., 2009. In vivo over-expression of interleukin-10 increases resistance to focal brain ischemia in mice. J. Neurochem. 110, 12-22.

Diederich, K., Sevimli, S., Dörr, H., Kösters, E., Hoppen, M., Lewejohann, L., Klocke, R., Minnerup, J., Knecht, S., Nikol, S., Sachser, N., Schneider, A., Gorji, A., Sommer, C., Schäbitz, W.R., 2009. The role of granulocyte-colony stimulating factor (G-CSF) in the healthy brain: a characterization of G-CSF-deficient mice. J. Neurosci. 29, 11572-11581.

England, T.J., Gibson, C.L., Bath, P.M., 2009. Granulocyte-colony stimulating factor in experimental stroke and its effects on infarct size and functional outcome: a systematic review. Brain Res. Rev. 62, 71-82.

Fagan, S.C., Hess, D.C., Hohnadel, E.J., Pollock, D.M., Ergul, A., 2004. Targets for vascular protection after acute ischemic stroke. Stroke 35, 2220-2225.

Gelderblom, M., Leypoldt, F., Steinbach, K., Behrens, D., Choe, C.U., Siler, D.A., Arumugam, T.V., Orthey, E., Gerloff, C., Tolosa, E., Magnus, T., 2009. Temporal and spatial dynamics of cerebral immune cell accumulation in stroke. Stroke 40, 1849-1857.

Hokari, M., Kuroda, S., Chiba, Y., Maruichi, K., Iwasaki, Y., 2009. Synergistic effects of granulocyte-colony stimulating factor on bone marrow stromal cell transplantation for mice cerebral infarct. Cytokine 46, 260-266.

Imai, Y., Ibata, I., Ito, D., Ohsawa, K., Kohsaka, S., 1996. A novel gene iba1 in the major histocompatibility complex class III region encoding an EF hand protein expressed in a monocytic lineage. Biochem. Biophys. Res. Commun. 224, 855-862.

Katayama, Y., Battista, M., Kao, W.M., Hidalgo, A., Peired, A.J., Thomas, S.A., Frenette, P.S. 2006. Signals from the sympathetic nervous system regulate hematopoietic stem cell egress from bone marrow. Cell 124, 407-421.

Kawada, H., Takizawa, S., Takanashi, T., Morita, Y., Fujita, J., Fukuda, K., Takagi, S., Okano, H., Ando, K., Hotta, T., 2006. Administration of hematopoietic cytokines in the subacute phase after cerebral infarction is effective for functional recovery facilitating proliferation of intrinsic neural stem/progenitor cells and transition of bone marrow-derived neuronal cells. Circulation 113, 701-710.

Komine-Kobayashi, M., Zhang, N., Liu, M., Tanaka, R., Hara, H., Osaka, A., Mochizuki, H., Mizuno, Y., Urabe, T., 2006. Neuroprotective effect of recombinant human granulocyte colony-stimulating factor in transient focal ischemia of mice. J. Cereb. Blood Flow Metab. 26, 402-413.

Lee, S.T., Chu, K., Jung, K.H., Ko, S.Y., Kim, E.H., Sinn, D.I., Lee, Y.S., Lo, E.H., Kim, M., Roh, J.K., 2005. Granulocyte colony-stimulating factor enhances angiogenesis after focal cerebral ischemia. Brain Res. 1058, 120-128.

Liu, S.P., Lee, S.D., Lee, H.T., Liu, D.D., Wang, H.J., Liu, R.S., Lin, S.Z., Shyu, W.C., 2010. Granulocyte colony-stimulating factor activating HIF- $1 \alpha$ acts synergistically with erythropoietin to promote tissue plasticity. PLOS ONE 5, e10093.

Levesque, J.P., Hendy, J., Takamatsu, Y., Simmons, P.J., Bendall, L.J., 2003. Disruption of the CXCR4/CXCL12 chemotactic interaction during hematopoietic stem cell mobilization induced by GCSF or cyclophosphamide. J. Clin. Investig. 111, 187-196.

Magrassi, L., Grimaldi, P., Ibatici, A., Corselli, M., Ciardelli, L., Castello, S., Podestà, M., Frassoni, F., Rossi, F., 2007. Induction and survival of binucleated Purkinje neurons by selective damage and aging. J. Neurosci. 27, 9885-9892.

Mezey, E., Chandross, K.J., Harta, G., Maki, R.A., McKercher, S.R., 2000. Turning blood into brain: cells bearing neuronal antigens generated in vivo from bone marrow. Science 290, 1779-1782

Minnerup, J., Heidrich, J., Wellmann, J., Rogalewski, A., Schneider, A., Schäbitz, W.R., 2008. Meta-analysis of the efficacy of granulocyte-colony stimulating factor in animal models of focal cerebral ischemia. Stroke 39, 1855-1861.

Mohr, J.P., Lazar, R.M., Marshall, R.S., Hier, D.B., 2004. Middle cerebral artery disease. In: Mohr, J.P., Choi, D.W., Grotta, J.C., Weir, B., Wolf, P.A. (Eds.), Stroke: Pathophysiology, Diagnosis and Management, pp. 123-165. Churchill Livingstone, PA.

Morita, Y., Takizawa, S., Kamiguchi, H., Uesugi, T., Kawada, H., Takagi, S., 2007. Administration of hematopoietic cytokines increases the expression of anti-inflammatory cytokine (IL10) mRNA in the subacute phase after stroke. Neurosci. Res. 58, 356-360.

Morrison, S.J., Wright, D.E., Weissman, I.L., 1997. Cyclophosphamideygranulocyte colony-stimulating factor induces hematopoietic stem cells to proliferate prior to mobilization. PNAS 94, 1908-1913.

Okabe, M., Ikawa, M., Kominami, K., Nakanishi, T., Nishimune, Y., 1997. 'Green mice’ as a source of ubiquitous green cells. FEBS Lett. 407, 313-319.

Popp, E., Rabsahl, T., Schneider, A., Russ, N., Spöhr, F., Vogel, P., Böttiger, B.W., Teschendorf, P., 2009. Intracerebroventricular application of granulocyte colonystimulating factor after cardiac arrest does not promote beneficial effects on cerebral recovery after cardiac arrest in rats. Resuscitation 80, 478-483.

Renolleau, S., Aggoun-Zouaoui, D., Ben-Ari, Y., Charriaut-Marlangue, C., 1998. A model of transient unilateral focal ischemia with reperfusion in the P7 neonatal rat: morphological changes indicative of apoptosis. Stroke 29, 1454-1460.
Schäbitz, W.R., Kollmar, R., Schwaninger, M., Juettler, E., Bardutzky, J., Schölzke, M.N., Sommer, C., Schwab, S., 2003. Neuroprotective effect of granulocyte colonystimulating factor after focal cerebral ischemia. Stroke 34, 745-751.

Schäbitz, W.R., Schneider, A., 2007. New targets for established proteins: exploring G-CSF for the treatment of stroke. Trends Pharmacol. Sci. 28, 157-161.

Schneider, A., Krüger, C., Steigleder, T., Weber, D., Pitzer, C., Laage, R., Aronowski, J., Maurer, M.H., Gassler, N., Mier, W., Hasselblatt, M., Kollmar, R., Schwab, S., Sommer, C., Bach, A., Kuhn, H.G., Schäbitz, W.R., 2005. The hematopoietic factor G-CSF is a neuronal ligand that counteracts programmed cell death and drives neurogenesis. J. Clin. Invest. 115, 2083-2098.

Schroeter, M., Jander, S., Witte, O.W., Stoll, G., 1999. Heterogeneity of the microglial response in photochemically induced focal ischemia of the rat cerebral cortex. Neuroscience 89, 1367-1377.

Schwarting, S., Litwak, S., Hao, W., Bähr, M., Weise, J., Neumann, H., 2008. Hematopoietic stem cells reduce postischemic inflammation and ameliorate ischemic brain injury. Stroke 39, 2867-2875.

Sehara, Y., Hayashi, T., Deguchi, K., 2007. Decreased focal inflammatory response by G-CSF may improve stroke outcome after transient middle cerebral artery occlusion in rats. J. Neurosci. Res. 85, 2167-2174.

Sevimli, S., Diederich, K., Strecker, J.K., Schilling, M., Klocke, R., Nikol, S., Kirsch, F., Schneider, A., Schäbitz, W.R., 2009. Endogenous brain protection by granulocytecolony stimulating factor after ischemic stroke. Exp. Neurol. 217, 328-335.

Six, I., Gasan, G., Mura, E., Bordet, R., 2003. Beneficial effect of pharmacological mobilization of bone marrow in experimental cerebral ischemia. Eur. J. Pharmacol. $458,327-328$

Solaroglu, I., Cahill, J., Tsubokawa, T., Beskonakli, E., Zhang, J.H., 2009. Granulocytecolony stimulating factor protects the brain against experimental stroke via inhibition of apoptosis and inflammation. Neurol. Res. 31, 167-172.

Stoll, G., Jander, S., Schroeter, M., 1998. Inflammation and glial responses in ischemic brain lesions. Prog. Neurobiol. 56, 149-171.

Strbian, D., Kovanen, P.T., Karjalainen-Lindsberg, M.L., Tatlisumak, T., Lindsberg, P.J., 2009. An emerging role of mast cells in cerebral ischemia and hemorrhage. Ann. Med. 1, 1-13.

Stroke Therapy Academic Industry Roundtable, 1999. Recommendations for standards regarding pre-clinical neuroprotective and restorative drug development. Stroke $30,2752-2758$

Taguchi, A., Wen, Z., Myojin, K., Yoshihara, T., Nakagomi, T., Nakayama, D., Tanaka, H., Soma, T., Stern, D.M., Naritomi, H., Matsuyama, T., 2007. Granulocyte colonystimulating factor has a negative effect on stroke outcome in a murine model. Eur. J. Neurosci. 26, 126-133.

Toth, Z.E., Leker, R.R., Shahar, T., Pastorino, S., Szalayova, I., Asemenew, B., Key, S., Parmelee, A., Mayer, B., Nemeth, K., Bratincsa, A., Mezey, E., 2008. The combination of granulocyte colony-stimulating factor and stem cell factor significantly increases the number of bone marrow-derived endothelial cells in brains of mice following cerebral ischemia. Blood 111, 5544-5552.

von Aulock, S., Diterich, I., Hareng, L., Hartung, T., 2004. G-CSF: boosting endogenous production-a new strategy? Curr. Opin. Investig. Drugs 5, 1148-1152.

Wang, H., Li, W., Zhu, S., Li, J., D'Amore, J., Ward, M.F., Yang, H., Wu, R., Jahnen-Dechent, W., Tracey, K.J., Wang, P., Sama, A.E., 2010. Peripheral administration of fetuin-A attenuates early cerebral ischemic injury in rats. J. Cereb. Blood Flow Metab. 30, 493-504.

Welte, K., Gabrilove, J., Bronchud, M.H., Platzer, E., 1996. MorstynG. Filgrastim (rmetHuG-CSF): the first 10 years. Blood 88, 1907-1929.

Wognum, A.W., Eaves, A.C., Thomas, T.E., 2003. Identification and isolation of hematopoietic stem cells. Arch. Med. Res. 34, 461-475.

Wright, D.E., Cheshier, S.H., Wagers, A.J., Randall, T.D., Christensen, J.L., Weissman, I.L., 2001. Cyclophosphamide/granulocyte colony-stimulating factor causes selective mobilization of bone marrow hematopoietic stem cells into the blood after M phase of the cell cycle. Blood 97, 2278-2285.

Yilmaz, G., Granger, D.N., 2009. Leukocyte recruitment and ischemic brain injury. Neuromolecular. Med. 12, 193-204.

Zhang, L., Shu, X.J., Zhou, H.Y., Liu, W., Chen, Y., Wang, C.L., Li, Y., Chen, O.X., Liu, L.J., Wang, J.Z., 2009. Protective effect of granulocyte colony-stimulating factor on intracerebral hemorrhage in rat. Neurochem. Res. 34, 1317-1323.

Zhao, L.R., Navalitloha, Y., Singhal, S., Mehta, J., Piao, C.S., Guo, W.P., Kessler, J.A., Groothuis, D.R., 2007a. Hematopoietic growth factors pass through the blood-brain barrier in intact rats. Exp. Neurol. 204, 569-573.

Zhao, L.R., Singhal, S., Duan, W.M., Mehta, J., Kessler, J.A., 2007b. Brain repair by hematopoietic growth factors in a rat model of stroke. Stroke 38, 2584-2591.

Zhao, L.R., Berra, H.H., Duan, W.M., Singhal, S., Mehta, J., Apkarian, A.V., Kessler, J.A., 2007c. Beneficial effects of hematopoietic growth factor therapy in chronic ischemic stroke in rats. Stroke 38, 2804-2811.

Zou, L., Barnett, B., Safah, H., LaRussa, V.F., Evdemon-Hogan, M., Mottram, P., Wei, S., David, O., Curiel, T.J., Zou, W., 2004. Bone marrow is a reservoir for CD4_CD25 regulatory $\mathrm{T}$ cells that traffic through CXCL12/CXCR4 signals. Cancer Res. 64, 8451-8455. 